\title{
How do changes in family role status impact employees? An empirical investigation
}

\author{
Matthew B. Perrigino \\ Iona College, New Rochelle, New York, USA \\ Ellen Ernst Kossek \\ Purdue University, West Lafayette, Indiana, USA \\ Rebecca J. Thompson \\ Independent Researcher, USA, and \\ Todd Bodner \\ Portland State University, Portland, Oregon, USA
}

Changes in family role status

Received 21 April 2021 Revised 27 May 2021 Accepted 28 May 2021

\begin{abstract}
Purpose - Despite the proliferation of work-family research, a thorough understanding of family role status changes (e.g. the gaining of elder or child caregiving responsibilities) remain under-theorized and under-examined. The purpose of this paper is to conceptualize various forms of family role status changes and examine the ways in which these changes influence various employee outcomes.

Design/methodology/approach - Data were collected as part of the work-family health study. Using a longitudinal, three-wave study with two-time lags of 6 months $(n=151$ family role status changes; $n=392$ individuals with family role stability), this study uses one-way analysis of variance to compare mean differences across groups and multilevel modeling to examine the predictive effects of family role status changes.
\end{abstract}

(C) Matthew B. Perrigino, Ellen Ernst Kossek, Rebecca J. Thompson and Todd Bodner. Published in Journal of Humanities and Applied Social Sciences. Published by Emerald Publishing Limited. This article is published under the Creative Commons Attribution (CC BY 4.0) licence. Anyone may reproduce, distribute, translate and create derivative works of this article (for both commercial and non-commercial purposes), subject to full attribution to the original publication and authors. The full terms of this licence maybe seen at http://creativecommons.org/licences/by/4.0/legalcode

This research was conducted as part of the Work, Family and Health Network (www. WorkFamilyHealthNetwork.org), which is funded by a cooperative agreement through the National Institutes of Health and the Centers for Disease Control and Prevention: Eunice Kennedy Shriver National Institute of Child Health and Human Development (Grant \# U01HD051217, U01HD051218, U01HD051256, U01HD051276); National Institute on Aging (Grant \# U01AG027669); the National Heart, Lung and Blood Institute (R01HL107240); Office of Behavioral and Social Sciences Research; and National Institute for Occupational Safety and Health (Grant \# U01OH008788, U01HD059773). Grants from the William T. Grant Foundation, Alfred P. Sloan Foundation and the Administration for Children and Families have provided additional funding. The contents of this publication are solely the responsibility of the authors and do not necessarily represent the official views of these institutes and offices. Special acknowledgment goes to Extramural Staff Science Collaborator, Rosalind Berkowitz King, $\mathrm{PhD}$ and Lynne Casper, $\mathrm{PhD}$, for the design of the original workplace, family, health and well-being network initiative. The findings and conclusions in this manuscript are those of the authors and do not necessarily represent the views of these institutes and offices.

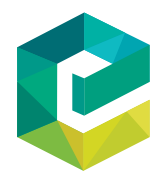

Journal of Humanities and Applied Social Sciences Vol. 4 No. 5,2022 . $393-409$ Emerald Publishing Limited 2632-279X DOI 10.1108/JHASS-04-2021-0075 


\section{JHASS 4,5}

Findings - Overall, experiences of employees undergoing a family role status change did not differ significantly from employees whose family role status remained stable over the same 12-month period. Separation/divorce predicted higher levels of family-to-work conflict.

Originality/value - The work raises important considerations for organizational science and human resource policy research to better understand the substantive effects of family role status changes on employee well-being.

Keywords Childcare, Marital status, Caregiving, Eldercare, Family role status, Family role status change, Work-family conflict, Perceived stress, Psychological distress

Paper type Research paper

\section{Introduction}

The emergence of work-family research - an area of study addressing the ways in which individuals experiences at work impact their experiences at home (and vice versa) - originally focused on samples of married employees with child caregiving responsibilities (Casper et al., 2007). More recently, the field has considered a wider variety of family-related roles, including those with elder caregiving responsibilities (Rofcanin et al., 2019), "sandwiched generation" employees providing care for both children and elders (Turgeman-Lupo et al., 2020) and single persons without children (Dumas and Perry-Smith, 2018). However, these investigations primarily consider family role status as a discrete cross-sectional variable, leaving family role status changes undertheorized in research and overlooked in practice.

The goal of our research is to offer deeper insights into this change element by considering whether the experiences of employees undergoing a family role status change differ compared to employees whose family role status remains stable for a given period. On the basis of work-family conflict theory (Greenhaus and Beutell, 1985), we argue that those undergoing a change in their personal lives (e.g. getting married or divorced) will experience higher levels of psychological distress, perceived stress and family-to-work conflict (FWC) (three of the most commonly examined employee well-being outcomes in the work-family literature) compared to those who are not currently undergoing such experiences. We examine this from two aspects:

(1) by comparing mean-differences across groups; and

(2) by using time-lagged data to determine whether the change is a predictor of the three aforementioned outcomes.

Our work makes multiple contributions. We offer insights into how scholars can think more longitudinally about family-related roles and their impact in the workplace, particularly in terms of how these changes matter for employee well-being. Moreover, our work bridges theory with practice by highlighting how organizational human resource (HR) policies often neglect these under-considered family role changes, despite the fact that strain associated with these different forms of family role status change impact absenteeism and productivity. We also provide a more holistic view of family role status changes that expands the breadth of current conceptualization beyond the traditional focus of marriage and parenthood (Dumas and Stanko, 2017): in addition to considering elder caregiving responsibilities, we also consider role losses in the cases of divorcees and those who relinquish child or elder caregiving responsibilities.

\section{Theory and hypotheses}

Individuals occupy multiple roles in both the work and nonwork domains (Kahn, Wolfe, Quinn, Snoek and Rosenthal, 1964). As explained through role accumulation theory 
(Sieber, 1974), individuals gain and lose these roles over the course of their lifetime. For example, one gains the role of a spouse through marriage yet loses this role through divorce. Elder caregiving roles are gained when an elder moves into the home and are lost either when the elder moves out (into an assisted care facility or to live on his or her own) or when the elder passes away. Child caregiving roles are gained at childbirth and are lost once the child grows up and moves out.

Work-family conflict theory considers the ways in which work and family may be incompatible with one another (Greenhaus and Beutell, 1985). For example, employees experience work-family conflict when a work event conflicts with a family event, as in the case of when a business meeting and a child's sporting event are scheduled at the same time. Employees also experience work-family conflict when strain from one domain impacts their experience in the other domain, as in the cases of how a fight with a spouse can make it more difficult for an individual to attend to his or her duties at work (family-to-work direction) or how a poor performance evaluation at work can make it more difficult for an individual to enjoy family time (work-to-family direction). Accordingly, we argue that family role status changes are likely to be associated with higher levels of perceived stress, psychological distress and FWC because of the additional demands and responsibilities they entail.

First, perceived stress is defined as individual perceptions associated with environmental demands, including major life events (Griffin and Clarke, 2011). Family role status changes constitute one type of these major life events, particularly in regard to the various forms of planning and preparation involved. For example, decisions about whether to take an elder into the home (i.e. gaining the role of elder caregiver) can take a toll as an individual or couple determines whether they have the necessary resources to properly provide informal care (Kossek, Colquitt and Noe, 2001). Parents preparing to help their child move to university may also experience stress associated with planning the move and fear over experiencing "empty nest syndrome" (Mitchell and Wister, 2015). Marriage can cause stress associated with wedding planning, while pregnancy and childbirth can cause stress in regard to preparing for the birth of the child. Divorces and separations can cause stress associated with awkwardness as ex-partners figure out how to interact among shared social circles (McDermott et al., 2013), while female divorcees experience a unique form of perceived stress in regard to deciding whether to revert to their original names (Hoffnung and Williams, 2016; Killewald, 2016).

Second, whereas perceived stress is relatively common and assesses individuals' perceptions, psychological distress is more severe in nature and focuses on individuals' mental health and depressive symptoms (Kossek et al., 2019 for a lengthier discussion of this distinction). Divorces and separations are associated with mortality, less happiness and increased psychological distress and may be particularly traumatic in situations where partner abuse exists (Rook and Zettel, 2005; Toews and Bermea, 2017). Divorces and situations where a partner passes involve experiences of grief and mourning (Celik and Caglayan, 2019; DePaulo and Morris, 2005; Kitson et al., 1980; Reed et al., 2016). Moreover, grief and mourning can occur when an elder passes away and caregiving is no longer required (Kossek, et al., 2001). After childbirth, mothers might experience post-partum depression (O'Hara and Swain, 1996). Stigmatization associated with childbirth can cause psychological distress when co-workers are unsupportive of the new parent (PaustianUnderdahl et al., 2019), while shame can cause psychological distress when the pregnancy is unplanned and the parents are unmarried (Morris and Munt, 2019).

Third, $F W C$ is the degree to which family-related demands are incompatible with workrelated demands (Greenhaus and Beutell, 1985). We focus on FWC, as same-domain effects including stressors and demands associated with family roles - are stronger and more direct
Changes in family role status

395 
JHASS 4,5

396

than cross-domain effects (Amstad et al., 2011; Michel, Mitchelson et al., 2010). As explained above, the undergoing of a family role status change can present new demands and strains that conflict with employees' work-related responsibilities and demands. In the case of marriage, for example, conflict can ensue as individuals seek to maximize their time experiencing the array of newly available intrinsic rewards in the form of joy, excitement and the gaining of companionship (Ashida et al., 2019). Various family role status changes involve different types of appointments that require time commitments - including those associated with doctor check-ups for soon-to-be-parents, divorce proceedings, wedding planning and settling the estate of an elder (Van den Eynde et al., 2019). Taken together, we anticipate that employees undergoing a family role status change - in comparison to employees whose family role status remains stable during the same period - will experience higher levels of perceived stress, psychological distress and FWC:

H1. Employees undergoing a family role status change will experience higher levels of perceived stress, psychological distress and FWC, compared to employees whose family role status remains stable.

Beyond an examination of mean differences, we also consider whether family role status changes explain any variance in the outcomes identified above. Byron's (2005) seminal metaanalysis found that various family-related demographic variables (e.g. number of children and marital status) had limited effects on experiences of FWC. We extend this inquiry through our discussion above it may be that employees whose family role status remains the same over an extended period of time become more adept and experienced at handling instances of FWC and the perceived stress and psychological distress that comes from maintaining such a status. To be clear, this stability does not necessarily preclude such experiences. However, we reason that the change process may be more disruptive, where individuals navigating change must figure out how to adjust and adapt. As a result, we hypothesize:

H2. The experience of a family role status change will be associated with higher levels of perceived stress, psychological distress and FWC.

\section{Methods}

Sample

The sample we use to test our hypotheses is part of the publicly archived data set for the work-family health study (WFHS), "a transdisciplinary research effort designed to enhance understanding of the impact of workplace practices and policies on work, family life and health outcomes" (Work Family Health Study, 2019). The sample is well-suited for examining family role status changes, as it followed employees over an extended period of time and collected data on a rolling basis. The three-time periods for the data collection were roughly July 2011 (Time 1; i.e. baseline), December 2011 (Time 2; i.e. 6 months) and June 2012 (Time 3; i.e. 12 months).

The WFHS is based on a group-randomized field experiment that occurred at two different organizations:

- the technology division of a Fortune 500 company; and

- an extended-care company operating nursing homes in the Northeastern USA (Work-Family Health Study, 2019; Bray et al., 2013). 
The data we used in our study came from the extended-care company. Because our interest in family role status changes was not related to the quasi-experimental research design, we limited our investigation to the 15 extended-care home sites that were in the control group (i.e. "usual practice") condition. This provided our investigation independence from the intervention and its effects, as our goal was to understand our results in the context of usual practice. Data collection occurred at each worksite during normal work hours. Participants were compensated in the form of a small monetary award to promote participation to remain in the study over time.

Our sample at Time 1 consisted of 799 respondents. On average, these employees were 38.97 years old $(\mathrm{SD}=12.37)$, worked $37.27 \mathrm{~h}$ per week $(\mathrm{SD}=7.77)$ and were predominantly female $(90.7 \%)$. At Time 2, complete data were received for 676 of the original 799 respondents (Average age $=39.17$ years, $\mathrm{SD}=12.78$; average hours worked $=37.55$, $\mathrm{SD}=7.81 ; 91.1 \%$ female). At Time 3 , we received complete data for 543 participants across all three measurement periods. This sample was $90.8 \%$ female, worked on average $37.76 \mathrm{~h}$ per week $(\mathrm{SD}=7.88)$ and was on average $39.71(\mathrm{SD}=12.28)$ years old. To detect any potential differences due to attrition, we used a one-way analysis of variance (ANOVA) to compare our final sample versus the participants who dropped out at Time 2 and Time 3. Compared to the participants who dropped out after Time 1, the final sample worked slightly more hours per week $(\mathrm{F}=6.477, p<0.01)$ and were slightly older $(\mathrm{F}=5.674, p<$ 0.05). Compared to the participants who dropped out after Time 2 , the final sample was slightly older $(\mathrm{F}=5.374, p<0.05)$. We did not have any reason to believe that these differences impacted our results presented below.

\section{Measures}

Family role status change

Measures of marital status, number of children living at home and elder caregiving responsibilities were collected at all three time periods. Marital status was coded as $1=$ married, $2=$ living with a romantic partner and $3=$ single. Elder caregiving responsibilities ("provides care for a relative") were coded as $1=$ yes and $2=$ no. Participants were also asked to report the number of children who lived at home for at least 4 days of the week. Our metric to determine a status change was to determine whether these reported values changed over time (similar to the approach used by Dumas and Stanko, 2017). For example, if someone with no children living at home at Time 1 reported one child living at home at Time 2 and/or Time 3, this was considered a family role status change. Shifts from single to either married or living with a romantic partner (or vice versa) also represented instances of family role status changes. In total, our final sample of 543 participants consisted of 151 individuals whose family role status changed and 392 participants whose family role status did not change over the 12-month period.

\section{The 12-month outcomes: Psychological distress, perceived stress and family-to-work conflict}

Perceived stress (12 months) was assessed with four items from Cohen et al. (1983). One sample item asked about the degree to which individuals felt "unable to control the important things in life." The five-point Likert scale ranged from $1=$ very often to $5=$ never and then was reverse-coded, with higher scores representing higher levels of perceived stress $(\alpha=0.74)$. Psychological distress (12 months) assessed the degree to which individuals felt "hopeless," "nervous," "worthless," "restless or fidgety," "so sad that nothing could cheer you up" and "everything was an effort" (Kessler et al., 2003). These items were scored on a five-point Likert scale ranging from $1=$ all of the time to $5=$ none of the time. Items were reverse-scored so that higher levels reflected greater psychological distress $(\alpha=0.87)$ 
JHASS

4,5

398

Despite similarities, Kossek et al. (2019) provide evidence for the conceptual and empirical distinction between the two constructs and measures within the context of the WFHS. While previous research suggests that these scales may be used as checklists (i.e. the sum of all items is taken as the individual score), we followed precedent in previous management research by taking the mean of all items so that all individual scores ranged from 1-5 (Evans, 2000).

FWC (12 months) was assessed using the five-item measure developed by Netemeyer, Boles and McMurrian (1996). A sample item is, "family-related strain interferes with your ability to perform job-related duties." These items were scored on a five-point Likert scale ranging from $1=$ strongly agree and $5=$ strongly disagree. Items were then reverse-coded, where higher scores indicated higher levels of FWC $(\alpha=0.84)$. This scale has been the most commonly used measure for FWC in longitudinal work-family studies and has been one of the most commonly used measures of work-family conflict (Nohe et al., 2015).

\section{Control variables}

The inclusion of control variables warrants justification (Bernerth and Aguinis, 2016). We controlled for worksite unit size as a continuous, level-2 (unit-level) variable based on the number of individuals within each worksite. We included this, as unit size influences individuals' experiences and perceptions within the workplace (Colquitt et al., 2002). As a level-1 (individual-level) variable, we controlled for a number of hours worked per week (reported as a continuous variable measured in hours), as the number of hours worked per week can produce additional strain and impact different health-related outcomes (Sparks et al., 1997; Ng and Feldman, 2008). We also included Time 1 measures of our outcomes: psychological distress (baseline), perceived stress (baseline) and FWC (baseline). These measures were based on the same scales noted above, with Cronbach alphas of $0.85,0.76$ and 0.81 , respectively. Inclusion of the outcome variable measured at a previous time point allows for more rigor in inferring causality among relationships (D'Innocenzo et al., 2016).

\section{Results}

Table 1 provides the means, standard deviations and Cronbach alphas for all of the variables of the study. H1 sought to compare mean differences between employees undergoing a family role status change $(n=151)$ and those whose status did not change $(n=392)$. Table 2 reports the means and standard deviations across the two groupings. An

\begin{tabular}{lrrrrrrrrr}
\hline Variable & M & SD & 1 & 2 & 3 & 4 & 5 & 6 & 7 \\
\hline Level 2 & & & & & & & & & \\
Unit size & 36.20 & 12.85 & -- & & & & & & \\
Level 1 & & & & & & & & & \\
Hours worked per week & 37.76 & 7.86 & -- & & & & & & \\
Psych. distress (baseline) & 1.97 & 0.75 & -0.03 & $(0.85)$ & & & & & \\
Perceived stress (baseline) & 2.36 & 0.76 & -0.05 & $0.65^{* *}$ & $(0.76)$ & & & & \\
FWC (baseline) & 2.04 & 0.56 & -0.08 & $0.19^{* *}$ & $0.22^{* *}$ & $(0.81)$ & & & \\
Psych. distress (12 months) & 1.87 & 0.72 & 0.01 & $0.64^{* *}$ & $0.45^{* *}$ & $0.16^{* *}$ & $(0.87)$ & & \\
Perceived stress (12 months) & 2.25 & 0.72 & -0.07 & $0.48^{* *}$ & $0.54^{* *}$ & $0.21^{* *}$ & $0.70^{* *}$ & $(0.74)$ & \\
FWC (12 months) & 2.06 & 0.54 & $-0.09^{*}$ & $0.20^{* *}$ & $0.17^{* *}$ & $0.40^{* *}$ & $0.25^{* *}$ & $0.26^{* *}$ & $(0.84)$
\end{tabular}

Correlations, means, standard deviations and reliabilities

Notes: $n=543$, nested within 15 worksites; $* * p<0.01 ; * p 0.05$ 
omnibus ANOVA test did not reveal any statistically significant group mean differences. Thus, $H 1$ was not supported.

H2 sought to address whether family role status changes predicted perceived stress, psychological distress and FWC. We used multilevel modeling procedures, as our data consisted of individual responses nested within different worksites (Raudenbush and Bryk, $2002)$ and created a dichotomous variable ( $0=$ no change; $1=$ family role status change) to enter into the model as a predictor. Table 3 shows that this variable approached significance as a predictor of $\mathrm{FWC}(\mathrm{B}=0.08, p<0.10)$, with the positive coefficient indicating that family role status changes are likely to predict higher levels of $\mathrm{FWC}$ compared to the predictive effects of (stable) family role status.

\section{Post hoc analyzes}

We sought to further probe the results above, particularly in regard to our recognition that different types of family role status changes are qualitatively different. For example, family role status changes involving marriage and childbirth are often fulfilling and happy (PerryJenkins et al., 2000) while the gaining of an elder caregiving role is "associated with a complex pattern of benefits and costs" due to the varying degrees with which elders can

\begin{tabular}{llcccccr}
\hline & & \multicolumn{2}{c}{ Psych. distress } & \multicolumn{2}{c}{ Perceived stress } & \multicolumn{2}{c}{ FWC } \\
Status change grouping & & Baseline & 12 mo. & Baseline & 12 mo. & Baseline & 12 mo. \\
\hline Family role status change & Mean & 2.05 & 1.93 & 2.34 & 2.27 & 2.01 & 2.11 \\
$(n=151)$ & SD & 0.86 & 0.86 & 0.80 & 0.79 & 0.52 & 0.53 \\
Stable/no family role status change & Mean & 1.94 & 1.85 & 2.37 & 2.24 & 2.06 & 2.04 \\
$(n=392)$ & SD & 0.71 & 0.67 & 0.75 & 0.70 & 0.58 & 0.55
\end{tabular}

Note: One-way ANOVA tests did not reveal any statistically significant group mean differences across the six variables
Changes in family role status

399

\begin{tabular}{|c|c|c|c|c|c|c|c|c|c|c|}
\hline & Psy & 1. distr & & Per & ived st & & & FWC & & \\
\hline Effects & $\underline{B}$ & $\underline{S E}$ & $\underline{p}$ & $\underline{B}$ & $\underline{S E}$ & $\underline{p}$ & $\underline{B}$ & $\underline{S E}$ & $\underline{p}$ & \\
\hline \multicolumn{11}{|l|}{ Fixed effects } \\
\hline Intercept & 0.56 & 0.17 & $* * * *$ & 1.40 & 0.20 & $* * *$ & 1.45 & 0.16 & $* * *$ & \\
\hline \multicolumn{11}{|l|}{ Control variables } \\
\hline Unit size & -0.00 & 0.00 & & -0.01 & 0.00 & $t$ & -0.00 & 0.00 & & \\
\hline Hours worked & 0.00 & 0.00 & & -0.00 & 0.00 & & -0.00 & 0.00 & & \\
\hline Outcome at baseline & 0.61 & 0.03 & $* * *$ & 0.50 & 0.03 & $* * *$ & 0.38 & 0.04 & $* * *$ & \\
\hline \multicolumn{11}{|l|}{ Predictor } \\
\hline Family role status change & 0.01 & 0.05 & & 0.05 & 0.06 & & 0.08 & 0.05 & $t$ & \\
\hline \multicolumn{11}{|l|}{ Random effects } \\
\hline Residual & 0.31 & 0.02 & $* * *$ & 0.36 & 0.02 & $* * *$ & 0.25 & 0.02 & $* * *$ & Table 3. \\
\hline Group & 0.00 & 0.01 & & 0.01 & 0.01 & & 0.00 & 0.00 & & Effects of family role \\
\hline $\operatorname{ICC}(1)$ & 0.02 & & & 0.03 & & & 0.00 & & & $\begin{array}{l}\text { Emects of ramily role } \\
\text { status change on }\end{array}$ \\
\hline \multicolumn{11}{|c|}{$\begin{array}{l}\text { Notes: } n=151 \text {; All variables with the exception of Unit Size are level-1 (individual level of analysis); }{ }^{\mathrm{t}} p<\quad \text { hypothesized } \\
0.10 ; * * *<<0.001\end{array}$} \\
\hline
\end{tabular}


JHASS 4,5

take care of themselves and to what extent they provide help with household chores (Ingersoll-Dayton et al., 2001, p. 263).

Accordingly, we split the 151 general "status changers" category into 13 distinct groups. First, we categorized individuals who experienced one change over the 12-month period into "separation/divorce," "married/cohabitating," "child gain," "child loss," "elder gain” and "elder loss." Second, we categorized individuals who experienced multiple changes, including: "marital status and child caregiving," "elder and child caregiving," "marital status and elder caregiving" and a triple category of "marital status, child and elder caregiving." One multiple changes, for example, is an instance where an employee begins cohabitating with or marries a partner with a child or elder dependent. Third, we included two dynamic categorizations: "elders in-and-out" and "on-again, off-again relationship." In both cases, individuals' responses at Time 2 were different from Time 1 and Time 3 for elder caregiving responsibilities and for married/cohabitating, respectively (hence, our use of all three time periods for assessing family role status change instead of assessing this at Time 1 and Time 3 only). Over the span of a year, for example, elders might move into and back out of the home (or vice versa) depending on their health or the financial situation, among other factors. Similarly, over the course of a year, a couple might move in together, experience a separation, but later make amends (or, perhaps, a new romantic relationship follows the previous one). To ensure the reliability and accuracy of self-report participant responses particularly these dynamic categorizations - additional questions were asked at Time 2 and Time 3 including "The previously recorded number of children living at home is correct" and "(not) married/partnered status has changed since the prior interview."

To re-examine $H 1$, a second omnibus ANOVA test revealed statistically group mean differences for the perceived stress (baseline) variable $(\mathrm{F}=1.913, p<0.05)$. However, posthoc Bonferroni and Scheffe tests did not detect statistically significant differences between any two single groupings (Table 4). This is likely due in part to the fact that the sample size for certain groupings is extremely small, yet also highlights the difficulty of considering multiple types of family role status changes at such a nuanced level.

To re-examine $H 2$, we again used multilevel modeling and created dummy coded variables to represent each of these categories in the analysis. Table 5 sheds light on the finding above: separation/divorce predicted higher levels of $\mathrm{FWC}(\mathrm{B}=0.27, p<0.05)$. While we also observe that the on-again, off-again relationship family role status change predicted higher levels of psychological distress and perceived stress, we are hesitant to draw this as a solid conclusion as only three individuals fit into this categorization.

\section{Discussion}

Our work extends current research highlighting the importance of family role status changes, explaining how changes in family role status - either gains or losses - impact employee well-being. While there were many similarities across different categories, we found that separation/divorce was associated with increased levels of FWC.

\section{Theoretical implications}

Our work advances theory by enhancing understanding of how family-related changes influence employee outcomes related to their health and well-being. In response to calls for integrating more time-based perspectives into the work-family literature (Matthews et al., 2014), we conceptualized family role status changes as instances where individuals gain or lose roles over time. While previous research primarily focuses on the gains, we extend this conceptualization to account for various role losses. 


\begin{tabular}{|c|c|c|c|c|c|c|c|c|}
\hline \multirow[b]{2}{*}{ Family role status change type } & & \multicolumn{2}{|c|}{ Psych. distress } & \multicolumn{2}{|c|}{ Perceived stress } & \multicolumn{2}{|c|}{ FWC } & \multirow{2}{*}{$\begin{array}{l}\text { Changes in } \\
\text { family role }\end{array}$} \\
\hline & & Baseline & $12 \mathrm{mo}$. & Baseline & $12 \mathrm{mo}$. & Baseline & $12 \mathrm{mo.}$ & \\
\hline Separation/divorce & Mean & 1.96 & 1.80 & 2.33 & 2.21 & 1.97 & 2.28 & \\
\hline$(n=21)$ & $S D$ & 0.82 & 0.92 & 0.78 & 0.82 & 0.56 & 0.45 & \\
\hline Married/cohabitating & Mean & 2.36 & 2.00 & 2.73 & 2.31 & 1.92 & 2.22 & \\
\hline$(n=12)$ & $S D$ & 1.23 & 0.72 & 1.01 & 0.66 & 0.74 & 0.57 & \\
\hline Child gain & Mean & 1.52 & 1.52 & 2.03 & 2.00 & 1.78 & 2.00 & 40 \\
\hline$(n=9)$ & $S D$ & 0.56 & 0.26 & 0.63 & 0.50 & 0.51 & 0.41 & \\
\hline Child loss & Mean & 2.03 & 2.00 & 2.96 & 2.63 & 2.07 & 2.07 & \\
\hline$(n=6)$ & $S D$ & 0.61 & 0.35 & 0.56 & 0.26 & 0.16 & 0.16 & \\
\hline Elder gain & Mean & 1.83 & 1.88 & 2.19 & 2.11 & 1.83 & 2.01 & \\
\hline$(n=16)$ & $S D$ & 0.90 & 0.99 & 0.97 & 0.93 & 0.41 & 0.87 & \\
\hline Elder loss & Mean & 1.97 & 1.90 & 2.05 & 2.19 & 2.10 & 2.10 & \\
\hline$(n=27)$ & $S D$ & 0.86 & 0.89 & 0.64 & 0.88 & 0.50 & 0.48 & \\
\hline Marital status and child caregiving & Mean & 2.07 & 1.87 & 2.48 & 2.13 & 2.16 & 2.10 & \\
\hline$(n=10)$ & $S D$ & 0.73 & 0.90 & 0.51 & 0.80 & 0.54 & 0.58 & \\
\hline Elder and child caregiving & Mean & 2.10 & 2.19 & 1.88 & 1.97 & 1.85 & 2.25 & \\
\hline$(n=8)$ & $S D$ & 0.77 & 1.14 & 0.67 & 0.92 & 0.38 & 0.46 & \\
\hline Marital status, elder caregiving and & Mean & 2.21 & 2.08 & 3.00 & 2.13 & 1.95 & 2.00 & \\
\hline child caregiving $(n=4)$ & $S D$ & 0.64 & 0.74 & 0.54 & 0.83 & 0.64 & 0.00 & \\
\hline Marital status and elder caregiving & Mean & 2.33 & 2.08 & 2.56 & 2.51 & 2.01 & 1.92 & \\
\hline$(n=22)$ & $S D$ & 0.86 & 0.89 & 0.81 & 0.74 & 0.49 & 0.54 & \\
\hline Elder in-and-out $(n=12)$ & Mean & 2.19 & 1.89 & 2.42 & 2.42 & 2.32 & 2.28 & \\
\hline & $S D$ & 0.94 & 0.88 & 0.86 & 0.61 & 0.54 & 0.40 & ble 4. \\
\hline On-again, off-again relationship $(n=3)$ & Mean & 1.83 & 2.44 & 1.92 & 3.17 & 2.13 & 2.07 & hd standard \\
\hline & $S D$ & 0.60 & 1.17 & 0.38 & 1.38 & 0.23 & 0.61 & deviations across \\
\hline Stable/no family role status change & Mean & 1.94 & 1.85 & 2.37 & 2.24 & 2.06 & 2.04 & hily role status \\
\hline$(n=392)$ & $S D$ & 0.71 & 0.67 & 0.75 & 0.70 & 0.58 & 0.55 & change grou \\
\hline
\end{tabular}

Our work harnesses the momentum of newer management perspectives focusing on single and childless employees (Dumas and Perry-Smith, 2018; Wilson and Baumann, 2015) and pregnant women (Jones et al., 2016; Little et al., 2015) in the workplace. We extend these views not only through recognition of the multiplicity of possible family role statuses but add to the theory around the fact that family role status does not represent a static characteristic. Conceptually and empirically, we explained how family role statuses can change in any number of ways - sequentially or simultaneously - and intersect with each other. Going forward, this intersectionality might be considered not only in terms of multiple family role status changes but also in the context of the diversity literature by comparing gender- or race-related differences.

Our conceptualization and discussion of family role status change also extend to additional literature beyond those on which we drew for our theorizing. Family role status change fits into the literature on norms and stigmatization associated with pregnancy and parenthood, as individuals experiencing these changes must manage not only the change process in terms of how they attempt to balance work and family but also impressions with co-workers and supervisors (Little, et al., 2015; Spitzmueller, et al., 2016; Vandello et al., 2013). Importantly, our work - and particularly the limited empirical differences across different groupings - demonstrates that there is much gray area to consider. For example, while separation/divorce is generally considered a negative experience, it might be an essential, positive tool for escaping an abusive or otherwise unhealthy relationship or marriage (Rook and Zettel, 2005). Thus, there are multiple angles from which to view even a 


\section{JHASS \\ 4,5}

\begin{tabular}{|c|c|c|c|c|c|c|c|c|c|}
\hline \multirow[b]{2}{*}{ Effects } & \multicolumn{3}{|c|}{ Psych. distress } & \multicolumn{3}{|c|}{ Perceived stress } & \multicolumn{3}{|c|}{ FWC } \\
\hline & $\underline{B}$ & $\underline{S E}$ & $\underline{p}$ & $\underline{B}$ & $\underline{S E}$ & $\underline{p}$ & $\underline{B}$ & $\underline{S E}$ & $\underline{p}$ \\
\hline \multicolumn{10}{|l|}{ Fixed effects } \\
\hline Intercept & 0.53 & 0.17 & $* * *$ & 1.37 & 0.20 & $* * *$ & 1.44 & 0.16 & $* * *$ \\
\hline Control variables & & & & & & & & & \\
\hline Unit size & 0.00 & 0.00 & & -0.01 & 0.00 & $t$ & -0.00 & 0.00 & \\
\hline Hours worked & 0.00 & 0.00 & & -0.00 & 0.00 & & -0.00 & 0.00 & \\
\hline Outcome at baseline & 0.62 & 0.03 & $* * *$ & 0.51 & 0.03 & **** & 0.39 & 0.04 & $* * *$ \\
\hline \multicolumn{10}{|l|}{ Predictors } \\
\hline Separation/divorce & -0.04 & 0.13 & & -0.01 & 0.14 & & 0.27 & 0.11 & * \\
\hline Married/cohabitating & -0.11 & 0.17 & & -0.08 & 0.18 & & 0.23 & 0.15 & \\
\hline Child gain & -0.08 & 0.19 & & -0.07 & 0.20 & & 0.04 & 0.16 & \\
\hline Child loss & 0.09 & 0.23 & & 0.11 & 0.25 & & 0.09 & 0.21 & \\
\hline Elder gain & 0.10 & 0.14 & & -0.06 & 0.15 & & 0.06 & 0.13 & \\
\hline Elder loss & 0.04 & 0.11 & & 0.12 & 0.12 & & 0.04 & 0.10 & \\
\hline Marital status and child caregiving & -0.05 & 0.18 & & -0.10 & 0.19 & & 0.02 & 0.16 & \\
\hline Elder and child caregiving & 0.26 & 0.20 & & -0.09 & 0.22 & & 0.28 & 0.18 & \\
\hline Marital status, elder and child caregiving & 0.02 & 0.12 & & -0.48 & 0.30 & & 0.00 & 0.25 & \\
\hline Marital status and elder caregiving & -0.01 & 0.12 & & 0.15 & 0.13 & & -0.11 & 0.11 & \\
\hline Elders in-and-out & -0.11 & 0.16 & & 0.18 & 0.18 & & 0.14 & 0.15 & \\
\hline On-again, off-again relationship & 0.66 & 0.32 & * & 1.15 & 0.35 & $* *$ & -0.00 & 0.29 & \\
\hline \multicolumn{10}{|l|}{ Random effects } \\
\hline Residual & 0.31 & 0.02 & $* * *$ & 0.36 & 0.02 & $* * *$ & 0.25 & 0.02 & \\
\hline Group & 0.01 & 0.00 & & 0.01 & 0.01 & & 0.00 & 0.00 & \\
\hline $\operatorname{ICC}(1)$ & 0.02 & & & 0.04 & & & 0.00 & & \\
\hline
\end{tabular}

Table 5.

Effects of distinct family role status changes on hypothesized outcomes

Notes: $n=151$; All variables with the exception of unit size are level-1 (individual level of analysis); ${ }^{\mathrm{t}} p<$ $0.10 ; * p<0.05 ; * * p<0.01 ; * * *<0.001$

single-family role status change and engage paradoxical thinking, identifying downsides of "positive" family role status changes and upsides of "negative" changes (Dumas and PerrySmith, 2018).

\section{Practical implications}

Beyond their prevalence, family role status changes are relevant to employers' HR practices because these role status changes:

- impact employee eligibility for many health care and other related benefits; and

- are often linked to a number of HR policies provided for by the using organization (e.g. parental leave policies).

Many employers - particularly those in the USA - provide health-care benefits for spouses/ partners and children through adult years (Connley, 2017). In addition to tracking the birth of a child and divorce to determine eligibility for employee benefits, employers often support wellness and dependent care spending accounts to provide pre-tax dollars for elder and child care expenses (Jack et al., 2006). Beyond its relevance in terms of employee benefits, divorce is costly for employers in terms of absenteeism and reduced productivity (Kocakulah et al., 2016; Kourlis, 2012). Around the world, elder caregiving is recognized as a "significant" issue for the twenty-first century (Zacher and Winter, 2011). The more caring and sensitive 
an organization can be in response to family role status changes, the more likely it is that it can recruit and retain top talent (Plaisier et al., 2015).

Organizations can consider training their managers to engage in family-supportive supervisor behaviors as a proactive means of offsetting or preventing any disruptions the family role status changes create for the employee or work unit as a whole (Hammer et al., 2009). Rather than counseling individual managers and employees only after a family role status change occurs, such training will prepare managers to be ready to support unanticipated changes in terms of their ability to provide emotional and instrumental support. Managers who provide this support to their employees are likely to have a closer relationship with their subordinates. In turn, subordinates who experience this support are likely to have improved job performance (Matthews et al., 2013; Odle-Dusseau et al., 2012). Pregnant employees whose managers are family support are likely to confide in their managers at an earlier point in time (Little, et al., 2015).

Our work offers implications for formal support in terms of the HR policies and programs provided by organizations designed to promote work-family balance. This might include simple fixes such as clarifying and communicating that flexible work arrangements can be used for additional family-related needs beyond childcare. Embedded within all of these suggestions is the necessity for organizations to de-stigmatize and remove any backlash-related effects associated with any type of family role status change (Perrigino et al., 2018).

\section{Limitations and future research}

Our study design has both strengths and weaknesses. On the one hand, the inclusion of 151 family role status changers to coincide with 392 individuals whose family status did not change is a strong design element. Given the time that the family role status change process can take to occur, we believe this sample size is well positioned in terms of representing a sample population that is difficult to access. Additionally, this data was collected as part of a field study, a design, which is useful to contextualize how family role status changes impact employees in a growing, stressful industry: health care. On the other hand, a significant limitation is that - in attempting to consider specific types of family role status change - our analyzes yielded few statistically significant results.

In total, 6 - and 12-month time lags are reasonable to assess family role status change, as they provide enough time for a status change to develop (e.g. the period from pregnancy to childbirth generally lasts 9 months). However, we did not specify the lags with our research questions in mind and the intervals were based on the convenience and practical limitations associated with the collection of field-based data (Zapf et al., 1996). Although panel designs are promising for assessing the time-based effects, future studies should consider theoretically plausible alternates for these intervals. It is highly likely that there are different appropriate time lags depending on the specific type of family role status change. At the same time, this makes a comparative analysis of different family roles' status changes more difficult. One interesting conundrum is whether individuals who do not experience family role status changes should be included as a comparative group: on the one hand, family role status changes are unlikely to occur on a frequent (e.g. daily) basis. On the other hand, as the time lags of any study increase, so too will the percentages of individuals experiencing a family role status change within a given sample.

Building on this point, sample composition deserves focused attention in future studies. Despite the virtues of a field study with multiple waves of data, our data is based on a 
JHASS 4,5

predominantly female sample from a single organization. To collect data on family role status change, multiple sample criteria must be met to provide for the greatest generalizability without sacrificing statistical power. Future studies might follow recent approaches to recruit samples to study a specific type of family role status change with specific types of questions to investigate (e.g. pregnant women and their anticipation of childbirth or even the anticipation of becoming pregnant; Gloor et al., 2018; Jones et al., 2016). In terms of invasiveness, many types of family role status changes - particularly shed roles - may bring up sensitive issues for which researchers must not only receive IRB approval but also handle with care when collecting data. This is a particularly salient point for research in cultures where knowledge and discussion of one's family situation in the workplace are considered too personal. In this regard, we encourage future research to include employee samples from non-US settings where family norms, dynamics and role expectations may differ.

Finally, we were unable to distinguish between some of the more nuanced family role status changes within our post-hoc analyzes. The 151 individuals who experienced family role status changes likely had 151 unique experiences and - while we were able to group some patterns together - we likely missed out on details that qualitative methods could uncover. It will be important for future research to distinguish whether patterns emerge based on whether elders in the home are healthy or sick. It was unclear in our data whether elders moved into the home so that they could provide assistance (e.g. with a newborn) because they required assistance or both (Ingersoll-Dayton et al., 2001). Given the various null findings, we do not believe that the ways in which we categorized groupings influenced our results.

Future research can address additional nuances on which our study missed out. For example, research points to differences between marriage and cohabitation, another category which we grouped together (Blekesaune, 2018). Our "child gain" category did not distinguish between whether the birth was a first child or subsequent child, while our "child loss" category - albeit small - did not identify the reason the child was no longer in the home. Although we considered changes in the number of children that a person had, there is a conceptual distinction between the roles of "parent" and "caregiver," as some parents are more or less involved in the actual caregiving responsibilities than others. The age of children is another important consideration: teenage children capable of assisting with care for younger children may be able to alleviate the caregiving burden of some parents. Moreover, there were some categorizations we did not consider, including "revolving doors" where adult children move back into the home (Dennerstein et al., 2002).

\section{Conclusion}

Our work underscores the complexity of family role status changes. Just as previous research noted that child caregiving needs are "diverse, multi-faceted and changing" (Kossek, 1990, p. 769), so too are employees' changing family role statuses evolving on many different fronts. Organizations will need to keep up with these changes to ensure adequate staffing levels and the retention of top talent. Our work takes the first steps toward:

- broadening work-family research to link such family role status changes to role enactment and involvement changes; and

- identifying and theorizing additional family role status changes that have important consequences for workplace phenomena. 


\section{References}

Amstad, F.T., Meier, L.L., Fasel, U., Elfering, A. and Semmer, N.K. (2011), "A Meta-analysis of workfamily conflict and various outcomes with a special emphasis on cross-domain versus matchingdomain relations", Journal of Occupational Health Psychology, Vol. 16 No. 2, pp. 151-169.

Changes in family role status

Ashida, S., Sewell, D.K., Schafer, E.J., Schroer, A. and Friberg, J. (2019), "Social network members who engage in activities with older adults: Do they bring more social benefits than other members?", Ageing and Society, Vol. 39 No. 5, pp. 1050-1069.

Bernerth, J.B. and Aguinis, H. (2016), "A critical review and best-practice recommendations for control variable usage”, Personnel Psychology, Vol. 69 No. 1, pp. 229-283, available at: https://doi.org/ 10.1111/peps.12103

Blekesaune, M. (2018), "Is cohabitation as good as marriage for people's subjective well-being? Longitudinal evidence on happiness and life satisfaction in the British household panel survey", Journal of Happiness Studies, Vol. 19 No. 2, pp. 505-520, available at: http://ink.springer.com/ 10.1007/s10902-016-9834-x

Bray, J.W., Kelly, E.L., Hammer, L.B., Almeida, D.M., Dearing, J.W., King, R.B. and Buxton, O.M. (2013), "An integrative, multilevel, and transdisciplinary research approach to challenges of work, family, and health", RTI Press publication No. MR-0024-1303, RTI Press, Research Triangle Park, NC.

Byron, K. (2005), “A Meta-analytic review of work-family conflict and its antecedents", Journal of Vocational Behavior, Vol. 67 No. 2, pp. 69-198.

Casper, W.J., Eby, L.T., Bordeaux, C., Lockwood, A. and Lambert, D. (2007), "A review of research methods in IO/OB work-family research", Journal of Applied Psychology, Vol. 92 No. 1, pp. 28-43, available at: http://dx.doi.org/10.1037/0021-9010.92.1.28

Celik, M. and Caglayan, N.İ. (2019), "Resilience as the predictor of divorcees' life satisfaction", Social Science Quarterly, Vol. 100 No. 6, pp. 2078-2093, available at: https://doi.org/10.1111/ ssqu. 12700

Cohen, S., Kamarck, T. and Mermelstein, R. (1983), “A global measure of perceived stress”, Journal of Health and Social Behavior, Vol. 24 No. 4, pp. 385-396, available at: https://www.jstor.org/stable/ 2136404

Colquitt, J.A., Noe, R.A. and Jackson, C.L. (2002), "Justice in teams: Antecedents and consequences of procedural justice climate", Personnel Psychology, Vol. 55 No. 1, pp. 83-109, available at: https:// doi.org/10.1111/j.1744-6570.2002.tb00104.x

Connley, C. (2017), "9 Companies hiring now that cover 100\% of employee health insurance premiums", available at: www.cnbc.com/2017/08/09/9-companies-that-cover-100-percent-of-employee-healthinsurance-premiums.html (accessed 28 August 2019).

D'Innocenzo, L., Luciano, M.M., Mathieu, J.E., Maynard, M.T. and Chen, G. (2016), "Empowered to perform: a multilevel investigation of the influence of empowerment on performance in hospital units", Academy of Management Journal, Vol. 59 No. 4, pp. 1290-1307, available at: https://doi. org/10.5465/amj.2013.1073

Dennerstein, L., Dudley, E. and Guthrie, J. (2002), "Empty nest or revolving door? A prospective study of women's quality of life in midlife during the phase of children leaving and re-entering the home", Psychological Medicine, Vol. 32 No. 3, pp. 545-550, available at: https://doi.org/10.1017/ S0033291701004810

DePaulo, B.M. and Morris, W.L. (2005), "Singles in society and in science”, Psychological Inquiry, Vol. 16 No. 2, pp. 57-83. No

Dumas, T.L. and Perry-Smith, J. (2018), "The paradox of family structure and plans after work: Why single childless employees may be the least absorbed at work", Academy of Management Journal, Vol. 61 No. 4, pp. 1231-1252, available at: https://doi.org/10.5465/ amj.2016.0086 


\section{JHASS 4,5}

Dumas, T.L. and Stanko, T.L. (2017), "Married with children: How family role identification shapes leadership behaviors at work", Personnel Psychology, Vol. 70 No. 3, pp. 597-633.

Evans, G.W. (2000), "Stress and open-office noise", Journal of Applied Psychology, Vol. 85 No. 5, pp. 779-783, available at: http://dx.doi.org/10.1037/0021-9010.85.5.779

Gloor, J.L., Li, X., Lim, S. and Feierabend, A. (2018), “An inconvenient truth? Interpersonal and career consequences of 'maybe baby' expectations", Journal of Vocational Behavior, Vol. 104, pp. 44-58, available at: https://doi.org/10.1016/j.jvb.2017.10.001

Greenhaus, J.H. and Beutell, N.J. (1985), "Sources of conflict between work and family roles", Academy of Management Review, Vol. 10 No. 1, pp. 76-88.doi:, doi: 10.5465/ AMR.1985.4277352.

Griffin, M.A. and Clarke, S. (2011), "Stress and well-being at work", in Zedeck, S. (Ed.), APA Handbook of Industrial and Organizational Psychology, Vol. 3. Maintaining, Expanding, and Contracting the Organization, American Psychological Association, Washington, DC, pp. 359-397, available at: http://dx.doi.org/10.1037/12171-010

Hammer, L.B., Kossek, E.E., Yragui, N.L., Bodner, T.E. and Hanson, G.C. (2009), "Development and validation of a multidimensional measure of family supportive supervisor behaviors (FSSB)", Journal of Management, Vol. 35 No. 4, pp. 837-856, available at: https://doi.org/10.1177/ 0149206308328510

Hoffnung, M. and Williams, M.A. (2016), “When Mr. Right becomes Mr. Wrong: Women’s postdivorce name choice", Journal of Divorce and Remarriage, Vol. 57 No. 1, pp. 12-35, available at: https:// doi.org/10.1080/10502556.2015.1113814

Ingersoll-Dayton, B., Neal, M.B. and Hammer, L.B. (2001), "Aging parents helping adult children: the experience of the sandwiched generation", Family Relations, Vol. 50 No. 3, pp. 263-271.doi, doi: 10.1111/j.1741-3729.2001.00262.x.

Jack, W., Levinson, A. and Rahardja, S. (2006), "Employee cost-sharing and the welfare effects of flexible spending accounts", Journal of Public Economics, Vol. 90 No. 12, pp. 2285-2301, available at: https://doi.org/10.1016/j.jpubeco.2006.04.003

Jones, K.P., King, E.B., Gilrane, V.L., McCausland, T.C., Cortina, J.M. and Grimm, K.J. (2016), “The baby bump: Managing a dynamic stigma over time”, Journal of Management, Vol. 42 No. 6, pp. 1530-1556, available at: https://doi.org/10.1177/0149206313503012

Kahn, R., Wolfe, D., Quinn, R., Snoek, J. and Rosenthal, R. (1964), Organizational Stress: Studies in Role Conflict and Role Ambiguity, Wiley, New York, NY.

Kessler, R.C., Barker, P.R., Colpe, L.J., Epstein, J.F., Gfroerer, J.C., Hiripi, E., Howes, M.J., Normand, S.L. T., Manderscheid, R., Walters, E.E. and Zaslavsky, A.M. (2003), "Screening for serious mental illness in the general population", Archives of General Psychiatry, Vol. 60 No. 2, pp. 184-189.

Killewald, A. (2016), "Money, work, and marital stability: Assessing change in the gendered determinants of divorce", American Sociological Review, Vol. 81 No. 4, pp. 696-719, available at: https://doi.org/10.1177/0003122416655340

Kitson, G.C., Lopata, H.Z., Holmes, W.M. and Meyering, S.M. (1980), "Divorcees and widows: Similarities and differences", American Journal of Orthopsychiatry, Vol. 50 No. 2, pp. 291-301, available at: http://dx.doi.org/10.1111/j.1939-0025.1980.tb03291.x

Kocakulah, M.C., Kelley, A.G., Mitchell, K.M. and Ruggieri, M.P. (2016), "Absenteeism problems and costs: causes, effects and cures", International Business and Economics Research Journal (IBER), Vol. 15 No. 3, pp. 89-96, available at: https://doi.org/10.19030/iber.v15i3.9673

Kossek, E.E. (1990), "Diversity in child care assistance needs: Employee problems, preferences and work-related outcomes", Personnel Psychology, Vol. 43 No. 4, pp. 769-791.

Kossek, E.E., Colquitt, J.A. and Noe, R.A. (2001), "Caregiving decisions, well-being, and performance: the effects of place and provider as a function of dependent type and work-family climates", Academy of Management Journal, Vol. 44 No. 1, pp. 29-44. 
Kossek, E.E., Thompson, R.J., Lawson, K.M., Bodner, T., Perrigino, M.B., Hammer, L.B., Buxton, O.M., Almeida, D., Moen, P., Hurtado, D.A., Wipfli, B., Berkman, L.F. and Bray, J.W. (2019), "Caring for the elderly at work and home: Can a randomized organizational intervention improve psychological health?”, Journal of Occupational Health Psychology, Vol. 24 No. 1, pp. 36-54, available at: http://dx.doi.org/10.1037/ocp0000104

Kourlis, R.L. (2012), "It is just good business: the case for supporting reform in divorce court", Family Court Review, Vol. 50 No. 4, pp. 549-557, available at: https://doi.org/10.1111/j.17441617.2012.01472.x

Changes in family role status

Little, L.M., Major, V.S., Hinojosa, A.S. and Nelson, D.L. (2015), "Professional image maintenance: How women navigate pregnancy in the workplace", Academy of Management Journal, Vol. 58 No. 1, pp. 8-37.

Matthews, R.A., Bulger, C.A. and Booth, S.M. (2013), "Managing the work-family interface to the benefit of both subordinates and supervisors: Looking beyond supervisor support and focusing on leadership behaviors", In Paludi, M. (Ed.), Psychology for Business Success: Juggling, Balancing, and Integrating Work and Family Roles and Responsibilities, Praeger, Santa Barbara, pp. 153-170.

Matthews, R.A., Wayne, J.H. and Ford, M.T. (2014), "A work-family conflict/subjective wellbeing process model: a test of competing theories of longitudinal effects", Journal of Applied Psychology, Vol. 99 No. 6, pp. 1173-1187, available at: http://dx.doi.org/10.1037/ a0036674

McDermott, R., Fowler, J.H. and Christakis, N.A. (2013), "Breaking up is hard to do, unless everyone else is doing it too: Social network effects on divorce in a longitudinal sample", Social Forces, Vol. 92 No. 2, pp. 491-519, available at: https://doi.org/10.1093/sf/sot096

Michel, J.S., Mitchelson, J.K., Pichler, S. and Cullen, K.L. (2010), “Clarifying relationships among work and family social support, stressors, and work-family conflict", Journal of Vocational Behavior, Vol. 76 No. 1, pp. 91-104, available at: https://doi.org/10.1016/j.jvb.2009.05.007

Mitchell, B.A. and Wister, A.V. (2015), "Midlife challenge or welcome departure? Cultural and familyrelated expectations of empty nest transitions", The International Journal of Aging and Human Development, Vol. 81 No. 4, pp. 260-280. https://doi.org/10.1177/0091415015622790

Morris, C. and Munt, S.R. (2019), "Classed formations of shame in white, british single mothers", Feminism and Psychology, Vol. 29 No. 2, pp. 231-249, available at: https://doi.org/10.1177/ 0959353518787847

Netemeyer, R.G., Boles, J.S. and McMurrian, R. (1996), "Development and validation of work-family conflict and family-work conflict scales", Journal of Applied Psychology, Vol. 81 No. 4, pp. 400-410, available at: http://dx.doi.org/10.1037/0021-9010.81.4.400

Ng, T.W. and Feldman, D.C. (2008), "Long work hours: a social identity perspective on Meta-analysis data”, Journal of Organizational Behavior, Vol. 29 No. 7, pp. 853-880, available at: https://doi.org/ 10.1002/job.536

Nohe, C., Meier, L.L., Sonntag, K. and Michel, A. (2015), "The chicken or the egg? A Meta-analysis of panel studies of the relationship between work-family conflict and strain", Journal of Applied Psychology, Vol. 100 No. 2, pp. 522-536, available at: http://dx.doi.org/10.1037/a0038012

O'Hara, M.W. and Swain, A.M. (1996), "Rates and risk of postpartum depression-a Meta-analysis", International Review of Psychiatry, Vol. 8 No. 1, pp. 37-54, available at: https://doi.org/10.3109/ 09540269609037816

Odle-Dusseau, H.N., Britt, T.W. and Greene-Shortridge, T.M. (2012), "Organizational work-family resources as predictors of job performance and attitudes: the process of work-family conflict and enrichment", Journal of Occupational Health Psychology, Vol. 17 No. 1, pp. 28-40, available at: http://dx.doi.org/10.1037/a0026428

Paustian-Underdahl, S.C., Eaton, A.A., Mandeville, A. and Little, L.M. (2019), "Pushed out or opting out? Integrating perspectives on gender differences in withdrawal attitudes during pregnancy", 


\section{JHASS 4,5}

Journal of Applied Psychology, Vol. 104 No. 8, pp. 985-1002, available at: https://doi.org/10.1037/ ap10000394

Perrigino, M.B., Dunford, B.B. and Wilson, K.S. (2018), "Work-family backlash: The "Dark Side" of Work-Life Balance (WLB) Policies", Academy of Management Annals, Vol. 12 No. 2, pp. 600-630. dark side" of work-life balance (WLB) policies. available at: https://doi.org/10.5465/ annals.2016.0077

Perry-Jenkins, M., Repetti, R.L. and Crouter, A.C. (2000), "Work and family in the 1990s", Journal of Marriage and Family, Vol. 62 No. 4, pp. 981-998, available at: https://doi.org/10.1111/j.17413737.2000.00981.x

Plaisier, I., Broese van Groenou, M.I. and Keuzenkamp, S. (2015), "Combining work and informal care: the importance of caring organisations", Human Resource Management Journal, Vol. 25 No. 2, pp. 267-280, available at: https://doi.org/10.1111/1748-8583.12048

Raudenbush, S.W. and Bryk, A.S. (2002), Hierarchical Linear Models: Application and Data Analysis Methods, 2nd ed., Sage, Newbury Park.

Reed, K., Lucier-Greer, M. and Parker, T.S. (2016), "Exploring parental divorce among emerging adult women: the roles of support networks and family relationships", Professional Psychology: Research and Practice, Vol. 47 No. 3, pp. 231-241. http://dx.doi.org/10.1037/pro0000090

Rofcanin, Y., Las Heras, M., Escribano, P.I. and Stanko, T. (2019), "FSSBs and elderly care: Exploring the role of organizational context on employees' overall health and work-family balance satisfaction”, Journal of Business and Psychology, Vol. 35 No. 3, pp. 403-419, available at: http:// dx.doi.org/10.1007/s10869-019-09629-8

Rook, K.S. and Zettel, L.A. (2005), "The purported benefits of marriage viewed through the lens of physical health", Psychological Inquiry, Vol. 16 No. 2-3, pp. 116-121, available at: www.jstor.org/ stable/20447272

Sieber, S.D. (1974), “Toward a theory of role accumulation”, American Sociological Review, Vol. 39 No. 4, pp. 567-578, available at: https://www.jstor.org/stable/2094422

Sparks, K., Cooper, C., Fried, Y. and Shirom, A. (1997), "The effects of hours of work on health: a Metaanalytic review", Journal of Occupational and Organizational Psychology, Vol. 70 No. 4, pp. 391-408, available at: https://doi.org/10.1111/j.2044-8325.1997.tb00656.x

Spitzmueller, C., Wang, Z., Zhang, J., Thomas, C.L., Fisher, G.G., Matthews, R.A. and Strathearn, L. (2016), "Got milk? Workplace factors related to breastfeeding among working mothers", Journal of Organizational Behavior, Vol. 37 No. 5, pp. 692-718.

Toews, M.L. and Bermea, A.M. (2017), "I was naive in thinking, 'I divorced this man, he is out of my life"': a qualitative exploration of post-separation power and control tactics experienced by women", Journal of Interpersonal Violence, Vol. 32 No. 14, pp. 2166-2189, available at: https://doi. org/10.1177/0886260515591278

Turgeman-Lupo, K., Toker, S., Ben-Avi, N. and Shenhar-Tsarfaty, S. (2020), "The depressive price of being a sandwich-generation caregiver: can organizations and managers help?", European Journal of Work and Organizational Psychology, Vol. 29 No. 6, pp. 862-879, available at: https:// doi.org/10.1080/1359432X.2020.1762574

Van den Eynde, A., Vercruyssen, A. and Mortelmans, D. (2019), "The experience of work-family conflict among divorced parents in Flanders", Journal of Divorce and Remarriage, Vol. 60 No. 6, pp. 447-478, available at: https://doi.org/10.1080/10502556.2019.1586227

Vandello, J.A., Hettinger, V.E., Bosson, J.K. and Siddiqi, J. (2013), "When equal isn’t really equal: the masculine dilemma of seeking work flexibility", Journal of Social Issues, Vol. 69 No. 2, pp. 303-321.

Wilson, K.S. and Baumann, H.M. (2015), "Capturing a more complete view of employees' lives outside of work: the introduction and development of new interrole conflict constructs", Personnel Psychology, Vol. 68 No. 2, pp. 235-282. 
Work-Family Health Study (2019), "Work, family, and health study (WFHS) (ICPSR 36158)", available at: https://doi.org/10.3886/ICPSR36158.v2

Zacher, H. and Winter, G. (2011), "Eldercare demands, strain, and work engagement: the moderating role of perceived organizational support", Journal of Vocational Behavior, Vol. 79 No. 3, pp. 667-680, available at: https://doi.org/10.1016/j.jvb.2011.03.020

Zapf, D., Dormann, C. and Frese, M. (1996), "Longitudinal studies in organizational stress research: a review of the literature with reference to methodological issues", Journal of Occupational Health Psychology, Vol. 1 No. 2, pp. 145-169, available at: http://dx.doi.org/10.1037/1076-8998.1.2.145

\section{Corresponding author}

Matthew B. Perrigino can be contacted at: mperrigino@iona.edu
Changes in family role status

For instructions on how to order reprints of this article, please visit our website: www.emeraldgrouppublishing.com/licensing/reprints.htm Or contact us for further details: permissions@emeraldinsight.com 